\title{
Role of Interpersonal Competencies in Academic Performance
}

\author{
* Dr. Ghulam Muhammad Awan \\ ** Dr. Rooh ul Amin (Corresponding Author) \\ *** Prof. Dr. Qadar Bakhsh Baloch
}

\begin{abstract}
This study aimed at examining the relationship between the role of interpersonal competencies and students' academic performance in the education sector of Pakistan. Students of Public sector universities operating in Peshawar, the capital of Khyber Pakhtunkhwa Pakistan were considered the population for the research. A stratified random sampling method was adopted for the selection of the sample. A survey method based on a questionnaire was applied for the collection of data. Before the conduction of the field survey, the validity of questionnaires was confirmed through a pilot study followed by an expertise review. A total of 328 questionnaires were administered and responses were received from 261 with duly filled questionnaires. The collected data was analyzed through SPSS and LISREL software. Analysis included Confirmatory Factor Analysis and Regression Analysis. CFA model fitness was evaluated based on seven fit indices and the model was significant and well fitted. Regression analysis was undertaken to examine the association amongst dependent variables and independent variables. Regression analysis values depict a positive significant association among communication skills and students' academic performance also show positive significant association among group/teamwork skills and students' academic performance. Students' findings were found consistent with previous studies conducted by (Latif 2006; Nasser, 2014; Nurmi, 2012; Korthagen, et al., 2014). The study recommended that at university level foundation course regarding the development of communication skills may be introduced to enhance the communication skills among students. It is also recommended that students may be engaged in interactive sessions for the development of their group/teamwork skills. The study further suggests that interactive seminars/workshops shall be arranged for students to exercise the importance of interpersonal competencies.
\end{abstract}

Keywords: Interpersonal Competencies, Communication Skills, Group/Teamwork \& Students' Academic Performance

\section{Introduction}

Competency referred to individual behavior or set of behaviors which is the outcome of knowledge, skill, and attitude including traits, motives, values, and beliefs that enables superior performance in a particular work context (Nasser, 2014). Students' interpersonal competency is students' ability to undertake group tasks and their communication skills without promoting conflict by establishing harmony. Literature highlights that student communication skills are a most driven element of interpersonal competency (Aylor, 2003; Dobransky \& Frymier, 2004; Tobbell \& O'Donnell, 2013). Interpersonal communication is usually outlined as communication undertaken amongst peoples dependent on each other in any context or they are interrelated at some level and possess some information of one another: for instance, communication amongst father and his son, workers and supervisor, a communication between siblings, and or students and teachers, so on (Cho, 2007). Though social communication is most frequently between pairs of people, it can also be extended to incorporate little intimate teams like the family. Interpersonal communication is developed or sustained based on faceto-face conversation, or based on using online platforms like social media, etc. Communication skill considering as the unit element of broad skills that are well-known and received great attention from academia (Kementerian et al., 2006). The broad skills cover many parts, this study would center on

\footnotetext{
* Department Peace and Conflict Studies, National Defense University [NDU], Islamabad, Pakistan Email: Sizova79@hotmail.com

** University of Wah, Wah Cantt, Pakistan Email: rua58@yahoo.com

*** Institute of Business Studies \& Leadership, Abdul Wali Khan University Mardan, Pakistan Email: drbalochqb@gmail.com
} 
communication skills. Latif and Roeckner (2006) state that key strategy to confirm that the country is ready to face all globalization challenges for survival and continuous economic process required to develop a great pool of human resource that provides sustainable dynamic supports to economic growth and enhance productivity. Communication could be an ability that is important in their existence. With the arrival of applicable communication, workers abilities to boost concepts and data moreover as a force of fine relationship with none issues, despite race, faith and social station. Consultants within the communications discipline argue that weak communication is the root reason for most issues and riches communication is the answer to most issues (Pearson \& Viscount Nelson, 2000). The core of scholars mainly concentrated on the development of interpersonal communication between students and lecturers. Moreover, the standard of social communication affects teaching standing, together with quality of teaching, and students' satisfaction. Thus students need to communicate befittingly and extensively with colleagues and teachers to gain confidence in their communication skills and enhance their educational performance (Nurmi, 2012). Essentially, it is more rewarding and prudent for the college and university students if the exercise for enhancement of interpersonal communication skills is linked with core subject study.

Interpersonal communication is not limited to considering the conversation or exchange of messages between two peoples or parts of a group rather it may adopt other styles like written. However, this type of communication includes the development and deliberation of the most significant application element of linear prototypical communication that is exclusively followed by all stakeholders of the message (Nurmi, 2012). This ensures that researchers might conclude that a clear and definite declaration of whatever has been transmitted. The role of the university in equipping students in different fields to meet the needs of the market focuses not only on educational attainment but also on the generic skills sets so-called soft skills that are needed to compete globally. Besides, companies now gave considerable importance to these generic skills set and characters while selecting potential workers of the company (Nasser, 2014).

Since 2008, the local educational institutes have specifically concentrated on generic abilities as a prerequisite of a particular degree and strongly associated with students' performance-based curriculum. Communication skills are an element of generic interpersonal skills that have been widely recognized at universities on a priority basis (Kementerian et al, 2006). Universities and colleges must also maintain and ensure whether graduates are provided with the opportunity to communicate confidently and concisely or otherwise. The facet of effective communication that undergraduate students need to be learned includes interpersonal skills. A detailed review of the literature on interpersonal communication skills identified numerous factors affecting the development of communication skills amongst students at various levels. A large number of factors have been discussed in the literature of interpersonal communication however, Dobransky and Frymier (2004) recommended the development and examination of interpersonal skills through a qualitative approach through existing theories already existing on the subject. Moreover, the growing interest in interpersonal skills should also be noticed from physiological and biological perspectives. Few concepts of interpersonal skills include knowledge and personality structures, verbal and non-verbal interaction or language particular or dominant emotional expression, and/or experience as well as social interaction or development of social network (Korthagen, 2014). Interpersonal skills set not only required at the workplace but it is very important and play significant role in every span of life (Roorda, Koomen, Spilt \& Oort, 2011). However, there is a lack of quality research in this area to conceptualize and operationally the impact of interpersonal competency on students' academic performance. For this purpose the following objectives were developed for this study:

i) To identify various components of interpersonal competencies among graduate students.

ii) To determine the impact of identified components on graduate students' performance.

\section{Statement of the Problem}

The demand for multi-skills human resources are significantly increasing over the years as most workplaces are equipped with advanced technology. In this regard, students require to learn interpersonal competencies skills for outstanding academic performance including communication skills and teamwork skills. Because an effective communication skill is also professional career concern skill. In the process of development Pakistan also required a workforce equipped with contemporary skilled including robust interpersonal communication and teamwork skills. This despite the importance of interpersonal competencies among the students to produced high skill intellectuals. 
Moreover according to Rahman (2000) more than $80 \%$ of graduates face difficulties in professional life due to low interpersonal competencies. Moreover, the growing interests in interpersonal skills are also noticed from physiological and biological perspectives. Few concepts of interpersonal skills include knowledge and personality structures, verbal and non-verbal interaction or language particular or dominant emotional expression, and/or experience as well as social interaction or development of social network (Korthagen, 2014). Interpersonal skills set not only required at the workplace and play a significant role in every span of life (Roorda, Koomen, Spilt \& Oort, 2011). Therefore, there is a need for exploring the role of competency amongst students in interpersonal communication and teamwork in improving their academic performance or otherwise in the Pakistani context. Because there is a scarcity of quality research on the construct, and operationalization of the concept i.e. the impact of interpersonal competency on student academic performance.

\section{Literature Review}

A 'Competency' is referred to the behavior or set of behaviors an individual performs or exhibits in a particular environment based on skill, knowledge, and past experiences while individual attitude comprised motives beliefs traits, and values that empower the individual to produce superior outcomes in a given context as compared to others (Tobbell \& O'Donnell, 2013). According to Avkiran (2000), competency is regarded as the specialty or possessing of particular skills that enable them to do superior outcomes effectively and efficiently. Moreover, it can be considered as the remarkable behavior of individuals that determines their learning abilities, skills, and experience. Accordingly, the communication competence or skill is related to the interpersonal participant insight to the level which this communication obliges to encounter interpersonal and personal requirement by sustaining the dependable superiority of such interaction (Carter \& Presnell, 1994). Further (Burleson \& Samter, 1990; Cegala 1981) described that it is an individual index of performance based on acquired knowledge to encounter how and when situations while using language skills in a particular context. Considering the above interpersonal competence also described as individual related behavioral aspects that motivate higher performance. Nevertheless, Axley (2016) states that interpersonal communication is a continuous process of receiving and transmitting evidence, feelings, attitudes, and beliefs while using different platforms of information sharing starting from face-to-face to social media or print media. Therefore, interpersonal communication is referred to individual ability, skills, and capability to effectively utilize communication as an effective and powerful tool to develop and sustain all types of relations (Zarrinabadi, 2014; Arroyo \& Harwood, 2011). Considering the above, teamwork and communication have been recognized as the most significant components of interpersonal competency (Vohra \& Satyanarayana 2002; Cegala 2015).

\section{Communication Skill}

Communication is defined as the process of exchange of knowledge, information, ideas, and thoughts by one person with another person(s) while using nonverbal and verbal techniques (Zarrinabadi, 2014). In general, the verbal method of communication has widely accepted across the world while using particular and easily understandable language. Communication is two ways process while one individual communicates or delivers the message and another individual or group of individuals receives it at the other end. According to Nasser (2014), effective communication involves the transmission and/or receiving of information, opinions, and ideas within a particular context and content. Despite verbal communication, data or so-called information may also be transmitted through pre-defined signs or symbols. In this regard, communication is defined as the giving or sharing of meaningful thoughts or ideas, or information while using any sort of media including verbal and nonverbal as well as symbolic conversation (Frymier, 2019). Communication always required two persons and medium of communication it start from sending or sharing of information, message (called sender or originator) being transferred through particular medium to receiver also called reader or listener with receiving of subsequent feedback from the receiver or listener (Sulaiman \& Masri, 1997). Considering the above definitions it is concluded that effective communication required the following elements; an individual or person who shared the information, the medium through which information is being shared or send, and at the other end a person is required to receive, listen, or read the information also provide feedback based on knowledge and ability. Literature review evident lack of communication skills amongst graduate students (Graham, 2019; Cleland, Foster \& Moffat, 2005). Further revealed that a positive association between the learning environment and student abilities to 
develop communication skills. In this regard graduate students are required to provide appropriate communication opportunities to learn effective communication as well as to equip themselves according to job market demand. The study further found that effective communication is the communication when the receiver or reader or listener easily understands as well as provides feedback based on acquired knowledge and skill. According to Nasser (2014), communication is counted as highly meaningful while all factors like social, spiritual, and physical are considered accordingly. Literature further found that those students who are neared to pursue their professional careers are required to avail all the opportunities that caused the development of interpersonal competencies for future success. As interpersonal competencies have been widely accepted skills, and highly demanded in all phrase of life, particular to professional life. Moreover, graduate students are required to focus on the development of communication skills for successful future prospective in professional career (Ihmeideh, et al. 2010). Researchers found several types of communication skills, however, mainly focused on written and verbal type of communication skills. Further Aylor (2003) found three essential types of communication that includes interpersonal communication, management communication (group communication at a time), and public communication. According to Nurmi (2012), effective communication includes verbal and nonverbal communication, written communication, and listener as well as feedback provider. Meanwhile, Myers (2012) also concludes that effective communication includes verbal, nonverbal, and written also required understanding and feedback to accomplish the purpose of communication. The world has become a global village and demanded that graduate students are required to equip themselves with effective communication skills that enable them to communicate in diverse contexts (Rubin et al., 2009). According to Wayne and Young (2013) graduate students are required to engage themselves in such activities that effectively develop their communication skills for future success in professional life.

\section{Conceptual Framework}

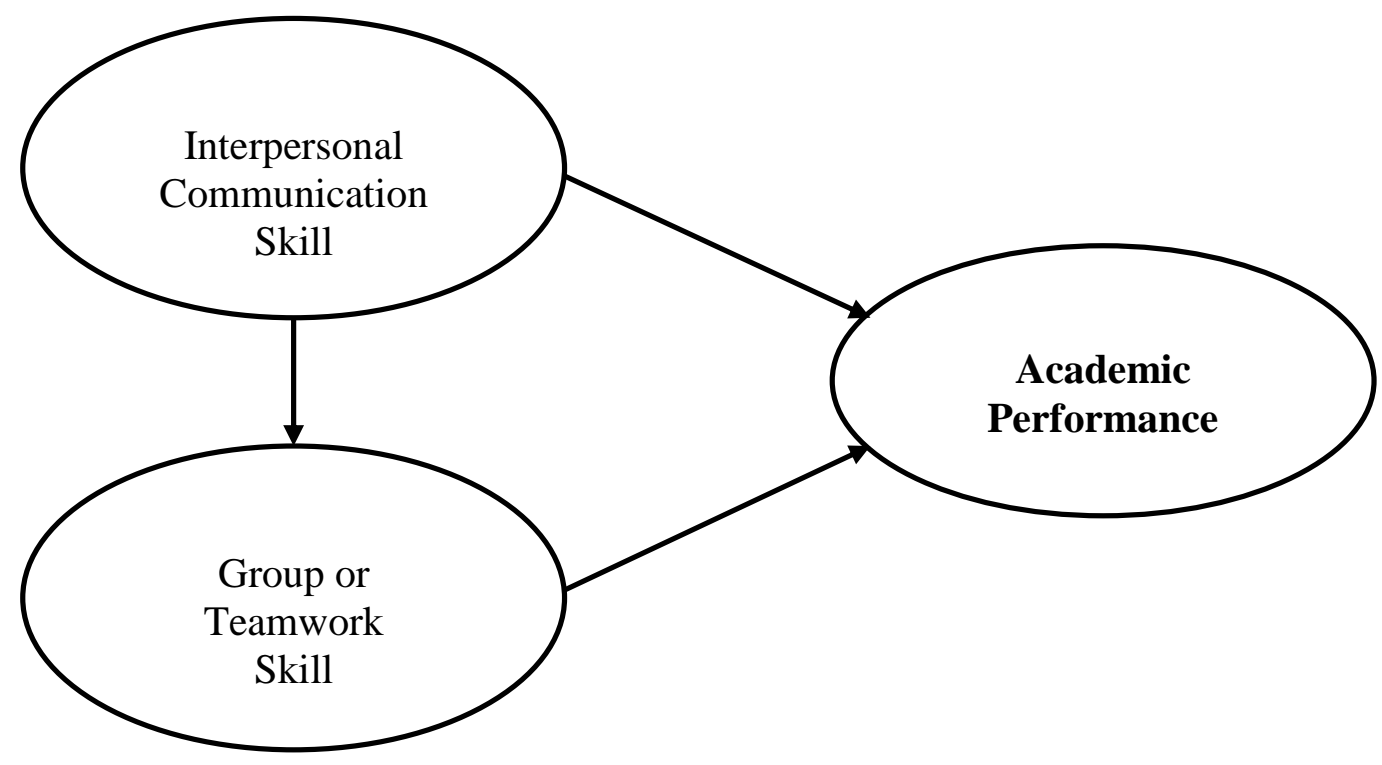

\section{Research Methodology}

This study was descriptive based on quantitative data collected through the survey method. Graduate students were considered population for this research; however, due to several constraints, the study was delimited to Management Sciences / Business Administrative departments of public sector universities operating in Peshawar region, capital of Khyber Pakhtunkhwa, Pakistan. A total of 528 questionnaires were distributed amongst selected students and responses were received from 261 students. The collected data was analyzed using SPSS and LISREL software.

\section{Data Analysis}

\section{Descriptive Statistic}

Table 1: $\quad$ Demographic values

\begin{tabular}{lllll}
\hline Description & & Frequency & Percent & Cumulative Percent \\
\hline \multirow{2}{*}{ Gender } & Male & 172 & 65.9 & 65.9 \\
University & Female & 89 & 34.1 & 100.0 \\
& University of Peshawar & 39 & 14.9 & 14.9
\end{tabular}


Total

$\begin{array}{llll}\text { Agriculture University } & 58 & 22.2 & 37.1 \\ \text { IM Sciences } & 47 & 18.0 & 55.1 \\ \text { Islamia College University } & 35 & 13.4 & 68.5 \\ \text { Sawabi Women University } & 29 & 11.2 & 79.7 \\ \text { BB Women University } & 53 & 20.3 & 100.0 \\ & \mathbf{2 6 1} & \mathbf{1 0 0 . 0} & \mathbf{1 0 0 . 0}\end{array}$

The above table shows the percentage of men and women respondents was $69.9 \%$ and $34.1 \%$ respectively. The table also shows the University wise Populations, figures depict that $17.9 \%$ of students belong to the University of Peshawar, 22.2\% belong to Agriculture University Peshawar, $18 \%$ to IM Sciences, $13.4 \%$ to Islamia College University Peshawar, only $11.2 \%$ belong to Sawabi Women University and $20.3 \%$ belong to Benazir Bhutto Women University Peshawar.

\section{Confirmatory Factor Analysis}

Confirmatory factor analysis (CFA) was applied to assess the fitness of the model.

CFA for communication skills and team or group work skills is as follows:



$\mathrm{X}^{2}=2.6, \mathrm{df}=1, \mathrm{P}=.002, \mathrm{RMSEA}=0.05$

CFA for Communication Skills and student academic performance is as follows:

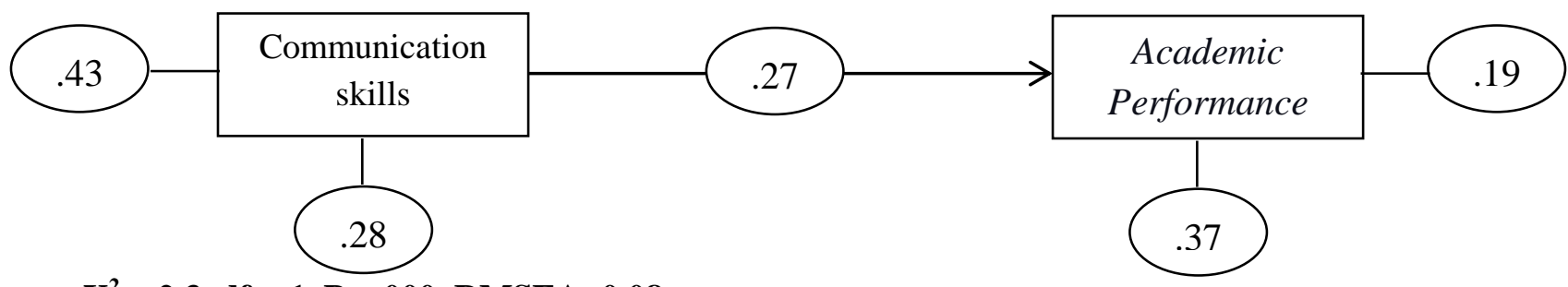

$\mathrm{X}^{2}=\mathbf{2 . 3}, \mathrm{df}=1, \mathrm{P}=.000, \mathrm{RMSEA}=0.08$

CFA for Teamwork skills and student academic performance is as follows:

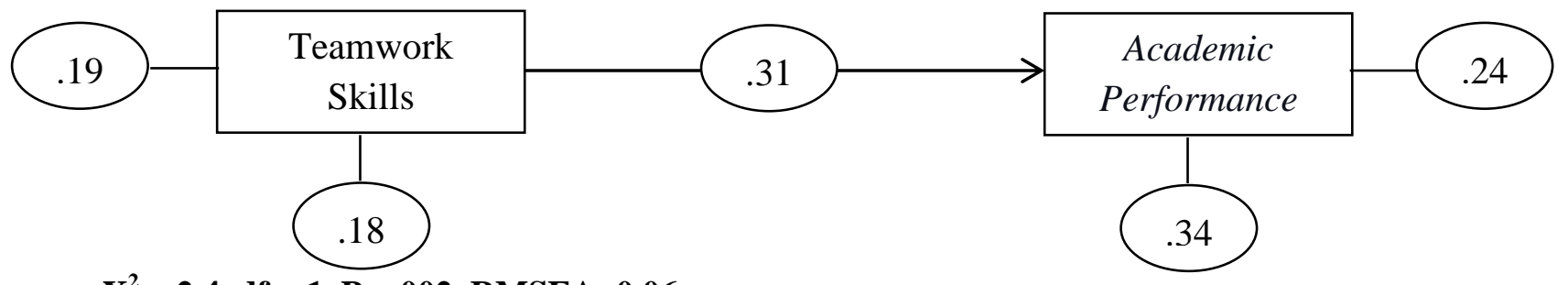

$\mathrm{X}^{2}=\mathbf{2 . 4}, \mathrm{df}=1, \mathrm{P}=.002, \mathrm{RMSEA}=0.06$

CFA model for all factors is as follows:

.26 \begin{tabular}{|c|}
\hline $\begin{array}{c}\text { Communication } \\
\text { Skills }\end{array}$ \\
\end{tabular}

Academic Performance

.39

Team/group work Skills

$\mathrm{X} 2=16.32, \mathrm{df}=6, \mathrm{P}=.008, \mathrm{RMSEA}=0.053$ 
Overall model goodness of fit

Table 2: Overall model fit indices

\begin{tabular}{llllllll}
\hline Factor model & NFI & AGFI & RMSEA & GFI & RMR & CFI & $\mathbf{X}^{2} / \mathbf{d f}$ \\
\hline Recommended values & $>.9$ & $>.8$ & $<.08$ & $>.9$ & $<.1$ & $>.9$ & $<.3$ \\
As per Uslu et al., (2008) & .97 & .92 & .05 & .98 & .03 & .97 & 2.6 \\
Model 1 & .92 & .96 & .08 & 91 & .05 & 1.01 & 2.3 \\
Model 2 & 1.02 & .98 & .06 & .94 & .04 & .91 & 2.4 \\
Model 3 & .95 & .89 & .05 & 1.07 & .08 & .95 & 2.72 \\
Model 5 (Full Factor Model) & .05
\end{tabular}

Construct: Communication skills, group/teamwork skills, and student academic performance

The statistic values of all models were found within an acceptable range and the model is well fitted.

Regression analysis

Regress analysis was conducted to examine the relationship amongst dependent variable and variable.

Table 3: $\quad$ Regress Model

\begin{tabular}{lllll}
\hline Model & R & R Square & Adjusted R Square & Std. Error of the Estimate \\
\hline 1 & .481 & .234 & .232 & .72223 \\
\hline
\end{tabular}

a. Predictor: (Constant), Communication skills and group/teamwork skills

Regression coefficient "R" $=.481(48 \%)$ association exist amongst communication skills, group/teamwork skills and student academic performance. The coefficient of determination $\mathrm{R}^{2}$ represents .234 indicate that $23.4 \%$ of variation exists among student academic performance is explained by interpersonal competencies.

Table 4: $\quad$ Coefficients

\begin{tabular}{llllll}
\hline & \multicolumn{3}{l}{ Unstandardized Coefficients } & \multicolumn{3}{l}{ Standardized Coefficients } & \\
\hline Model & $\boldsymbol{\beta}$ & Std.Error & Beta & T & Sig. \\
(Constant) & -.814 & .267 & & -3.46 & .001 \\
Communication skills & .092 & .043 & .084 & 3.65 & .013 \\
Group/teamwork skills & .385 & .031 & .337 & 6.47 & .002 \\
\hline
\end{tabular}

DV: Student Academic Performance

The coefficient $(\beta)$ value shows that a one percent change in communication skills changes $92 \%$ of student academic performance. The $\mathrm{T}$ value is found 3.65 and significant at .013 which is found within acceptable range i.e. $\mathrm{P}<.05$. This shows that communication skill has positive significant relationship with student academic performance. The coefficient $(\beta)$ value shows that a one percent change in-group/teamwork skill change $38.5 \%$ student academic performance. The $\mathrm{T}$ value found 6.47 and the significant value is .002 within acceptable range i.e. $\mathrm{P}<.05$. This shows that group/teamwork skill has positive significant association with student academic performance.

\section{Conclusion and Discussion}

This study aims to examine the role of interpersonal competencies and students' academic performance in the education sector of Pakistan. For this purpose, public sector universities operating in the Peshawar region were considered population, and a stratified sampling method was adopted for the selection of sampling size. A survey method based on a questionnaire was applied for the collection of data. Before conduct a field survey the validity of questionnaires was confirmed through a pilot study followed by an expertise review. The suggested corrections were made in the questionnaire and finally, 328 questionnaires were disseminated among the participants, and responses were received from 261. The collected data was analyzed through SPSS software. Analysis includes Confirmatory Factor Analysis and Regression Analysis. The model fitness of CFA model fitness is evaluated based on seven fit indices. The model statistic shows that model is significant and well fitted. Further, regression analysis was undertaken to examine the association amongst dependent variables and independent variables. Regression analysis values depict a positive significant association among communication skills and student academic performance also show a positive significant association between group/teamwork skills and student academic performance. Student findings were found consistent with previous studies conducted by (Latif 2006; Nasser, 2014; Nurmi, 2012; Korthagen, et al., 2014).

\section{Recommendations}

1. It is recommended that at university level course regarding the development of communication skills may be introduced to enhance the communication skills among students. 
2. It is further suggested that a seminar/workshop may be arranged for students to exercise the importance of interpersonal competencies.

3. It is recommended that students may be engaged in activities regarding the development of group/teamwork skills.

\section{References}

Arroyo, A., \& Harwood, J. (2011). Communication competence mediates the link between shyness and relational quality. Personality and Individual Differences, 50, 264-267.

Avkiran, N. (2000). Interpersonal skills and emotional maturity influence the entrepreneurial style of bank managers. Personnel Review, 29(5), 654-675.

Axley, S. R. (2016). Communication at work: Management and the communication-intensive organization. Praeger Pub Text.

Aylor, B. (2003). The impact of sex, gender, and cognitive complexity on the perceived importance of teacher communication skills. Communication studies, 54(4), 496- 509.

Baksh Baloch, Q., Saleem, M., Zaman, G., \& Fida, A. (2014). The Impact of Emotional Intelligence on Employees' Performance. Journal of Managerial Sciences, 8(2).

Baloch, Q. B., \& Inam, M. (2009). Strategic Competitiveness: Creating Firm's Future. Journal of Managerial Sciences, 3(1).

Baloch, Q. B., \& Siddiq, A. (2016). Role of Strategic Leadership in Competitive Healthcare Services: A Case Study of Hospitals in Pakistan. PUTAJ-Humanities and Social Sciences, 23(1), 89-100.

Baloch, Q. B., \& Jamshed, J. (2017). Service quality attributes and customer loyalty: A case study of Pakistan International Air Line. FWU Journal of Social Sciences, 11(1), 92.

Burleson, B. R., \& Samter, W. (1990). Effects of cognitive complexity on the perceived importance of communication skills in friends. Communication Research, 17, 165-182.

Carter, K., \& Presnell, M. (Eds.). (1994). Interpretive Approaches to Interpersonal Communication: The Aftermath of Counterinsurgency in Guatemala. SUNY Press

Cegala, D. J. (1981). Interaction involvement: A cognitive dimension of communicative competence. Communication Education, 30(2), 109-121.

Cegala, D. J. (2015). Interaction Involvement: a cognitive dimension of communication competence. Communication Education, 30, 109-121.

Cho, H., Geri, G., Davidson, B., \& Ingraffea, A. (2007). Social networks, communication styles, and learning performance in a CSCL community. Computers \& Education, 49, 309-329.

Dobransky, N. D., \& Frymier, A. B. (2004). Developing teacher-student relationships throughout class communication. Communication Quarterly, 52(3), 211-223.

Frymier, B. A. (2019). Students' classroom communication effectiveness. Communication Quarterly, 53(2), 197-212.

Graham, E. E. (2019). Communication Functions Questionnaire (CFQ). In Rubin, B. B., Rubin, A. M., Graham, E. E., Perse, E. M., Seibold, D. R. (Coord.), Communication research measures II: a sourcebook. New York: Routledge, pp.130-137.

Kementerian Pengajian Tinggi Malaysia (2006). Modul pembangunan kemahiran insaniah (soft skills) untuk institusi pengajian tinggi Malaysia. Serdang: Universiti Putra Malaysia, 1-52.

Korthagen, F. A. J., Noordewier, S. A., \& Zwart, R. C. (2014) Teacher-student contact: Exploring a basic but complicated concept. Teaching and Teacher Education, 40, 22-32.

Latif, M., \& Roeckner, E. (2006). Ocean circulation and tropical variability in the coupled model ECHAM5/MPI-OM. Journal of Climate, 19(16), 3952-3972

Myers, S. A., Martin, M. M., \& Knapp, J. L. (2005). Perceived instructor in-class communicative behaviors as a predictor of student participation in out-of-class communication. Communication Quarterly, 53(4), 437-450.

Nasser, F. (2014). Willingness to communicate in English, communication self-confidence, motivation, shyness and teacher immediacy among Iranian English-major undergraduates: A structural equation modeling approach. Learning and Individual Differences, 30, 140-147.

Nurmi, J-E. (2012). Students' characteristics and teacher-child relationships in instruction: A metaanalysis. Educational Research Review, 7, 177-197.

Qamar, F., \& Baloch, Q. B. (2017). Reviving Tourism through Entrepreneurial Capabilities in Swat, Dir \& Chitral Triangle in Post Operation Environment. Journal of Managerial Sciences, 11(2)

Pearson, J. C., \& Nelson, P. E. (2000). An introduction to human communication: Understanding and sharing. McGraw-Hill. 
Rahman, A., \& Hailes, S. (2000). Supporting trust in virtual communities. In Proceedings of the 33rd annual Hawaii international conference on system sciences (pp. 9-pp). IEEE.

Roorda, D. L., Koomen, H. M. Y., Spilt, J. L., \& Oort, F. J. (2011). The influence of affective teacher-student relationships on students' school engagement and achievement: a metaanalytic approach. Review of Educational Research, 81(4), 493-529.

Rubin, B. B., Rubin, A. M., Graham, E. E., Perse, E. M., \& Seibold, D. R. (2009). Communication research measures II: a sourcebook, New York: Routledge.

Shah, N. A. S. E. E. B., \& Baloch, Q. B. (2018). Comparison amid the Service Quality Attributes: Pakistan Hotel Industry Analyses. Journal of Business \& Tourism, 4(1), 239-247.

Tobbell, J., \& O'Donnell, V. L. (2013). The formation of interpersonal and learning relationships in the transition from primary to secondary school: Students, teachers and school context. International Journal of Educational Research, 59, 11-23.

Vohra, A., \& Satyanarayana, T. (2002). Statistical optimization of the medium components by response surface methodology to enhance phytase production by Pichia anomala. Process Biochemistry, 37(9), 999-1004.

Wayne, A. J., \& Young, P. (2003). Teacher characteristics and student achievement gains: A review. Review of Educational Research, 73(1), 89-122.

Zarrinabadi, N. (2014). Communicating in a second language: Investigating the effect of teacher on learners' willingness to communicate. System, 42, 288-295. 